\title{
An Experimental Study of the Uniaxial Failure Behaviour of Rock-Coal Composite Samples with Pre-existing Cracks in the Coal
}

\author{
Shaojie Chen $\left(\mathbb{D},{ }^{1}\right.$ Yao Ge, ${ }^{1}$ Dawei Yin ${ }^{1},{ }^{1,2}$ and Huisan Yang ${ }^{1}$ \\ ${ }^{1}$ State Key Laboratory of Mine Disaster Prevention and Control, Shandong University of Science and Technology, \\ Qingdao 266590, China \\ ${ }^{2}$ Key Laboratory of Safety and High-efficiency Coal Mining, Ministry of Education, Anhui University of Science and Technology, \\ Huainan 232001, China \\ Correspondence should be addressed to Dawei Yin; 949251142@qq.com
}

Received 19 June 2019; Revised 19 September 2019; Accepted 14 November 2019; Published 28 November 2019

Academic Editor: Vassilis Sarhosis

Copyright (C) 2019 Shaojie Chen et al. This is an open access article distributed under the Creative Commons Attribution License, which permits unrestricted use, distribution, and reproduction in any medium, provided the original work is properly cited.

\begin{abstract}
Many hazards encountered during coal mining can be caused by the instability and failure of the composite structure of the coal seam and the surrounding rock strata. The defects present in the coal affect the structural stability of the composite structure. In this study, uniaxial compression tests were conducted on sandstone-coal composite samples with pre-existing cracks in the coal, combined with tests performed with an acoustic emission (AE) device and a digital video camera. The strength, macrofailure initiation (MFI), and failure characteristics of composite samples, as influenced by the coal's pre-existing cracks, were analysed. The coal's pre-existing cracks were shown to reduce the strength, promote the occurrence of MFI, and affect the failure characteristics of the samples. Vertical penetration cracks had much more pronounced effects on strength and MFI occurrence, especially vertical penetration cracks that penetrated through the centre of the coal. Horizontal penetration cracks had a much reduced effect on strength and MFI occurrence. The MFI caused a step shape in the stress-strain curve accompanied with a peak energy index signal and occurred around the original coal cracks. The MFI models predominantly exhibited crack initiation from the pre-existing coal cracks and surface spalling caused by crack propagation. The intact composite sample failure presented as an instantaneous failure, whereas the composite samples containing the pre-existing cracks showed a progressive failure. The failures of composite samples occurred predominantly within the coal and displayed an X-typed shear failure accompanied by a small splitting failure. Both the coal and sandstone were destroyed in the composite sample with vertical penetration cracks through the centre of the coal. Failure of the coal occurred through a splitting failure accompanied by a small X-typed shear failure, while the sandstone showed a splitting failure induced by crack propagation in the coal.
\end{abstract}

\section{Introduction}

The area being mined in a coal-mining operation is essentially a composite structure consisting of coal seam and surrounding rock strata. The instability and failure of the composite structure can cause many hazards during coal mining, such as rock bursts and coal bumps, resulting in potential safety hazards to coal production [1-6]. However, the coal seam generally contains many more pre-existing defects than the rock stratum, which seriously affects the stability of the composite structure [7-10]. Therefore, it is important to investigate the effect of pre-existing defects in the coal on the mechanical behaviour of the composite structure.

A lot of investigations have been performed in the past on the mechanical behaviour of composite structures composed of coal seam and surrounding rock strata [1-7, 9-21]. In previous laboratory tests and numerical simulations, the composite structure was generally simplified as a composite sample of rock and coal with a bonded or frictional interface in order to study its mechanical behaviour $[1-7,9-21]$. The effects of rock strength 
and rock to coal height ratio on the strength and failure characteristics of rock-coal composite samples were studied by Liu et al. [2] and Chen et al. [11], respectively. Zhao et al. studied the failure characteristics of a threebody model composed of rocks and coal that varied in strength and stiffness [12]. The effects of loading rates on the strength, failure, and acoustic emission (AE) characteristics of a rock-coal-rock composite sample and a rockcoal composite sample under uniaxial loading and cyclic loading and unloading were studied by Huang and Liu [1] and Chen et al. [13], respectively. Moreover, the mechanical behaviour and failure characteristics of various types of composite samples (such as rock-coal-rock, rockcoal, and coal-rock) were contrastingly studied and analysed by Zhang et al. [14]. Among the samples, the strength of the rock-coal-rock composite sample was the highest. The rock-coal contact surface affected the mechanical failure behaviour of the composite samples. The effects of the cohesive strength of the interface and the interface angle on the strength and failure characteristics of rockcoal composite samples were studied by Zhao et al. [15] and Zhao et al. [16], respectively. Tan et al. studied the rockburst liability of composite samples [17, 18]. Poulsen et al. studied the strength reduction due to water saturation in a coal pillar embedded in roof rock-coal pillarfloor rock combined body [19]. Wang et al. studied the sliding mechanism of a composite sample [20].

The abovementioned studies and their attendant results and conclusions are important in order to understand the mechanical behaviour of composite structures consisting of a coal seam and surrounding rock strata. However, these investigations focused on relatively intact composite samples. Both preliminary testing results and theoretical analysis indicated obvious correlations between the initial coal defects and the mechanical properties of the composite samples. There are few studies on the effects of initial coal defects on the mechanical behaviour of the composite structure. Yin et al. investigated the effects of joint length and angle in coal on the strength and failure characteristics of rock-coal and rock-coal-rock composite samples using Particle Flow Code (PFC) [9-11].

Generally, in the edge of the composite structure firstly occurs instability and failure [3, 4], which is approximately in the state of uniaxial compression [9-11, 13]. Therefore, in this study, we performed uniaxial compression tests on sandstone-coal composite samples with pre-existing cracks in the coal. The effects of the preexisting coal cracks on the strength, macrofailure initiation (MFI), and failure characteristics of composite samples were studied.

\section{Materials and Methods}

As the structure of internal microcracks within coal can be quite complicated, in this study, only rock-coal composite samples with penetrative cracks or surface cracks in the coal were selected for the uniaxial compression tests. The sample preparation and test conditions are presented in detail in this section.
2.1. Sample Preparation. The rock and coal in the composite samples were taken from the immediate roof and coal seam in the 3306 working face of Daizhuang coal mine located in Shandong Province of China. The average mining depth is about $323 \mathrm{~m}$ (below the surface). The immediate roof is sandstone, and its average thickness is $4.07 \mathrm{~m}$. The average thickness of the coal seam is $1.45 \mathrm{~m}$, and its average dip angle is $12^{\circ}$. The uniaxial compression tests were conducted on standard pure coal and sandstone samples to obtain their mechanical properties, as shown in Table 1 [21].

The rock and coal blocks taken from the coal mine were core drilled to form cylindrical samples with a diameter of $50 \mathrm{~mm}$. The cylindrical samples of coal and rock were cut into $50 \mathrm{~mm}$ long sections with $50 \mathrm{~mm}$ diameter $(\Phi 50)$ using a stone-sawing machine. To reduce secondary damage to the coal and sandstone samples, the thrust and rotational speed of the core-drilling and stone-sawing machines were all set to their minimum possible levels. To meet the experimental requirements, both ends of the coal and rock samples were trimmed flat and smooth, respectively, using a stone grinding machine. The parallel misalignment of two ends should be less than $0.005 \mathrm{~cm}$; the dimensional deviation of two end faces should be less than $0.02 \mathrm{~cm}$; and two end faces must be perpendicular to its axis [1]. For research convenience, the height ratio of sandstone to coal was set to $1: 1$. Finally, based on previous investigations on composite structure [1-12, 15-20, 22], the coal and rock samples of $\Phi 50 \times 50 \mathrm{~mm}$ were bonded using thinning superglue to form standard rock-coal composite samples of $\Phi 50 \times 100 \mathrm{~mm}$.

The distributions of the pre-existing coal cracks in composite samples are presented in Table 2. It should be noted that all coal rocks were cracked to some extent. However, the coal sample with minimal critical cracks and the lowest persistence was considered an intact coal (nocrack coal) reference sample. A-1 composite sample, as shown in the table, with the lowest crack intensity, persistence, and total number was selected to represent the intact or reference sandstone-coal composite sample.

2.2. Testing System and Method. The testing system consisted of a loading frame, an acoustic emission (AE) monitoring system, and a digital video camera (DVC), as shown in Figure 1. During testing, the data from the loading system, $\mathrm{AE}$ monitoring system, and DVC were simultaneously recorded.

An electronic Shimadzu AUTOGRAPH (AG-X250) universal testing machine was selected as the loading system. A double screw loading structure was used for working flexibility. The testing system can execute conventional compression, tensile, or any other mechanical tests, as required. The maximum achievable testing load was $250 \mathrm{kN}$. To control fracture and crack growth, a displacement loading method was adopted in these tests at a loading rate of $0.0005 \mathrm{~mm} / \mathrm{s}$.

A MISTRAS AE instrument (Physical Acoustics Corporation, Princeton Jct, NJ, USA) was utilized to monitor the energy index characteristics of the composite sample over the entire duration of the test. The average gain of the main amplifier of the $\mathrm{AE}$ monitoring system was $40 \mathrm{~dB}$ with a 
TABLE 1: Mechanical properties of standard pure coal and rock samples [21].

\begin{tabular}{lccc}
\hline Group & Uniaxial compression strength (UCS) & Elastic modulus & Poisson's ratio \\
\hline Standard pure coal sample & $109.3 \mathrm{MPa}$ & 6.64 & 0.194 \\
Standard sandstone sample & $39.4 \mathrm{MPa}$ & 2.67 & 0.232 \\
\hline
\end{tabular}

TABle 2: Distributions of pre-existing coal cracks [5].

No. Composite sample photos $\quad$ Main distribution of pre-existing coal cracks

A-2
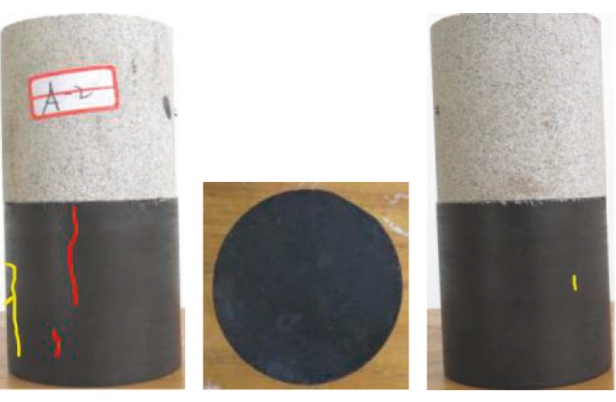

Two large vertical surface cracks, one adjacent to the rock-coal interface and the other in the middle and lower part of the coal
A-3
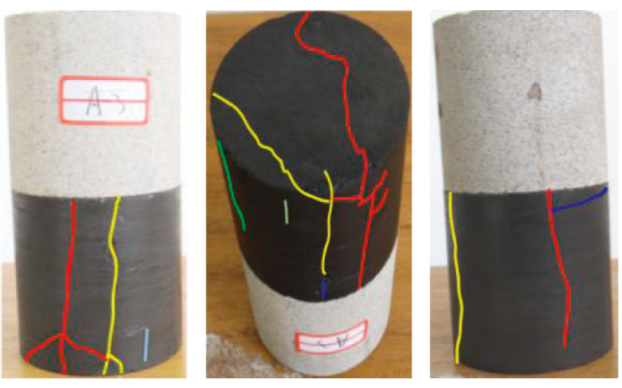

Two vertical penetrative side cracks through the coal near the lateral boundary
A- 4
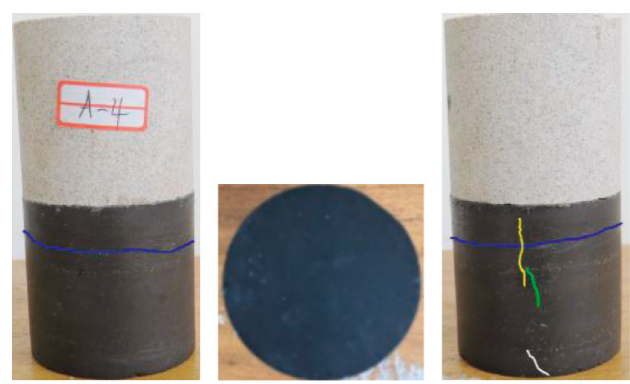

One horizontal penetrative crack and some surface cracks 
TABLE 2: Continued.

No. Composite sample photos
A-5 Main distribution of pre-existing coal cracks

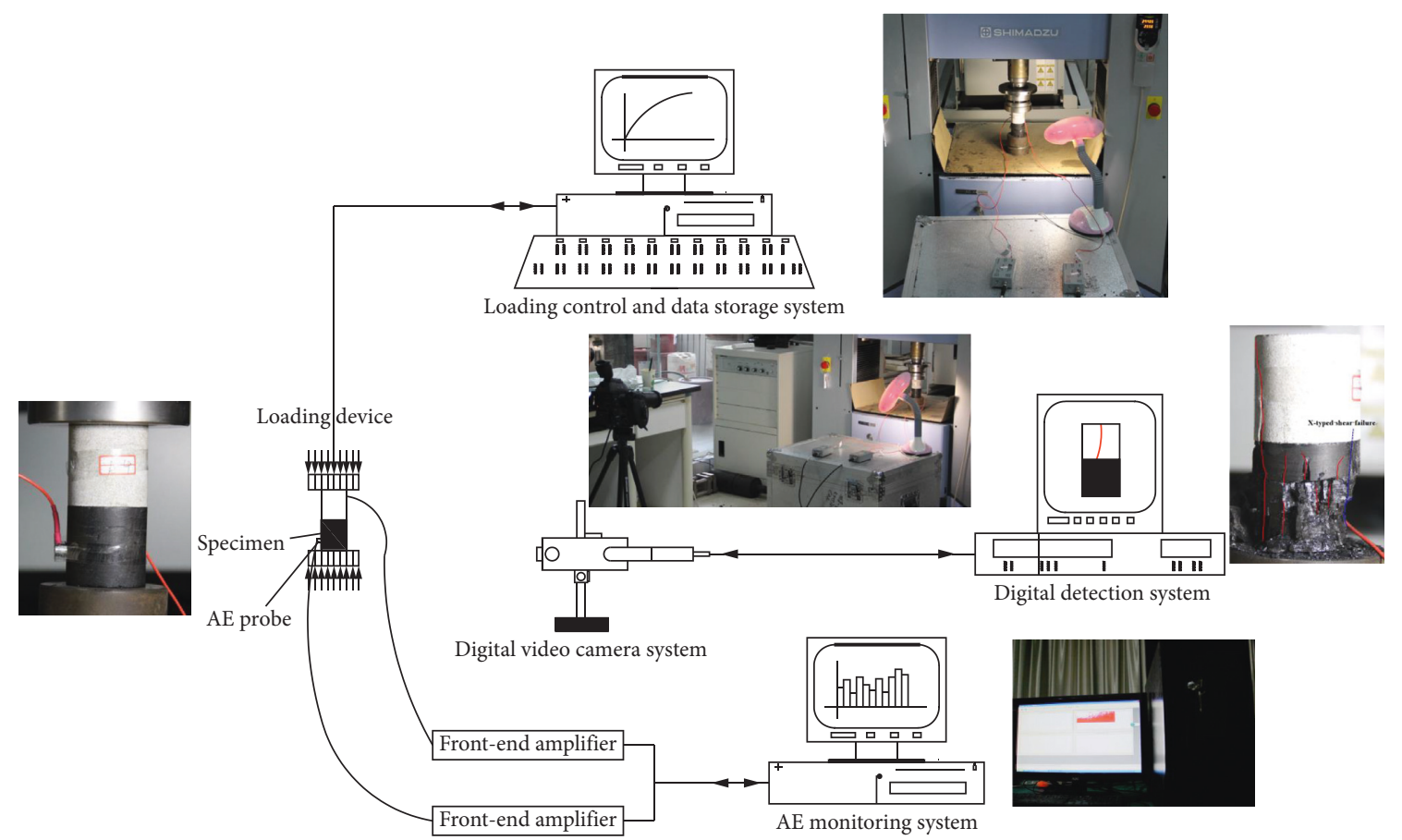

Figure 1: Test equipment and monitoring system.

maximum threshold value of $45 \mathrm{~dB}$ and a floating tolerance of $6 \mathrm{~dB}$. The two monitoring sensors were both Nano $30 \mathrm{AE}$; operating at a harmonic frequency range of 100 to $400 \mathrm{kHz}$ and a sampling rate of $10 \mathrm{MHz}$. The two $\mathrm{AE}$ sensors were installed on the surface of the sandstone and coal and fixed in place with appropriate tape. Vaseline was applied to the contact area between the sensors and the samples to ensure superior coupling conditions. The pencil-lead fracture method proposed by ASTM (2000) was used to calibrate the AE system. A SONY portable digital camera was used to record the failure process of the composite samples during exposure to uniaxial compression.

\section{Results and Discussion}

3.1. Strength Characteristics of the Composite Samples. The uniaxial compressive stress-strain curves for the composite samples are presented in Figure 2. The uniaxial compressive strengths (UCSs) of the composite samples are presented in Figure 3.

The UCSs of the composite samples containing preexisting coal cracks were clearly lower than that of the intact composite sample, and the pre-existing coal cracks exerted a deteriorating influence on the structural strength of the composite sample. The strength of sandstone is far greater than that of coal in the composite sample. Therefore, in a composite sample, the coal with the lower strength determines the structural strength of the composite sample [2-17]. In addition, the instability and failure of the composite samples was caused by the failure of the coal. In this investigation, the failures of composite samples A-1 to A-4 occurred predominantly within the coal, and no apparent failure was observed in the sandstone. The failures of the A-5 composite sample occurred within both the coal and the sandstone. The coal experienced splitting failure, and its propagation induced the ensuing splitting failure in the sandstone, which was 


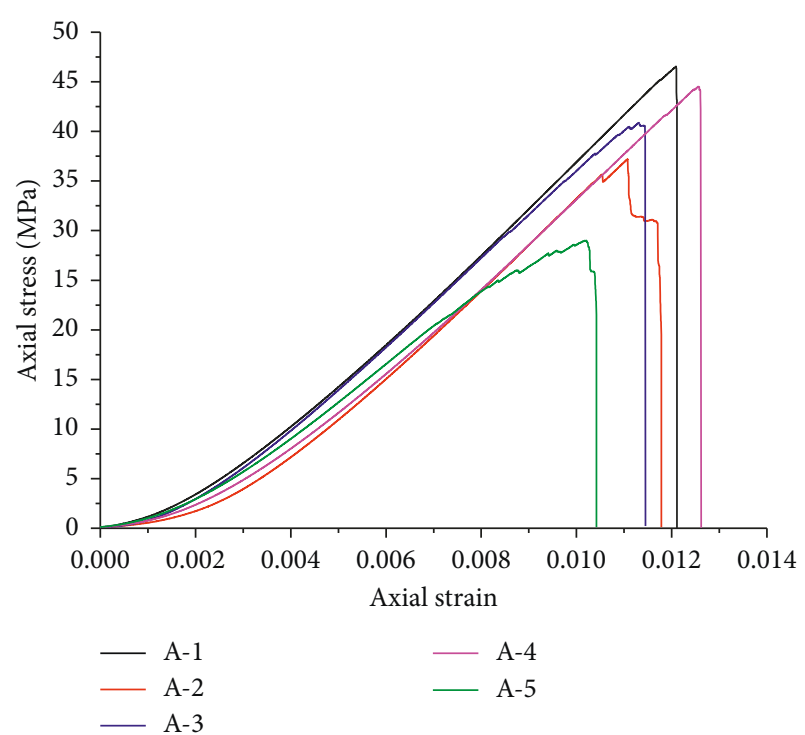

FIgURE 2: Uniaxial compressive stress-strain curves.

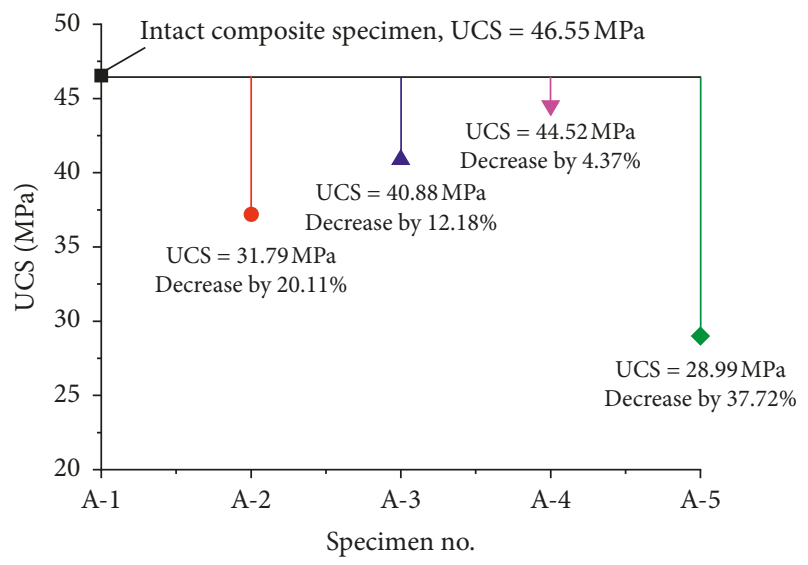

FIGURE 3: UCS comparison.

determined through post-test visual inspection of the sample. Therefore, the deteriorating influence of the pre-existing coal cracks on the structural strength occurred predominantly within the coal, decreasing its strength which led to a decrease in the composite's structural strength.

In order to analyse the strength of composite samples containing pre-existing coal cracks, the stress state of the coal in the composite sample was analysed as follows. According to the stress states of coal in the rock-coal-rock composite sample and rock-coal composite sample $[2,3,11,12,15,22]$, the stress state of coal in the sandstonecoal composite samples was established, as shown in Figure 4 . The elastic moduli of sandstone and coal were represented by $E_{S}$ and $E_{C}\left(E_{S}>E_{C}\right)$, respectively, and Poisson's ratios were represented by $u_{S}$ and $u_{C}\left(u_{S}<u_{C}\right)$, respectively. Under uniaxial stress $\sigma$, the lateral deformation of the coal near the sandstone-coal contact surface was limited to a certain extent by the sandstone [9-11]. However, the lateral deformation of the sandstone near the contact surface was

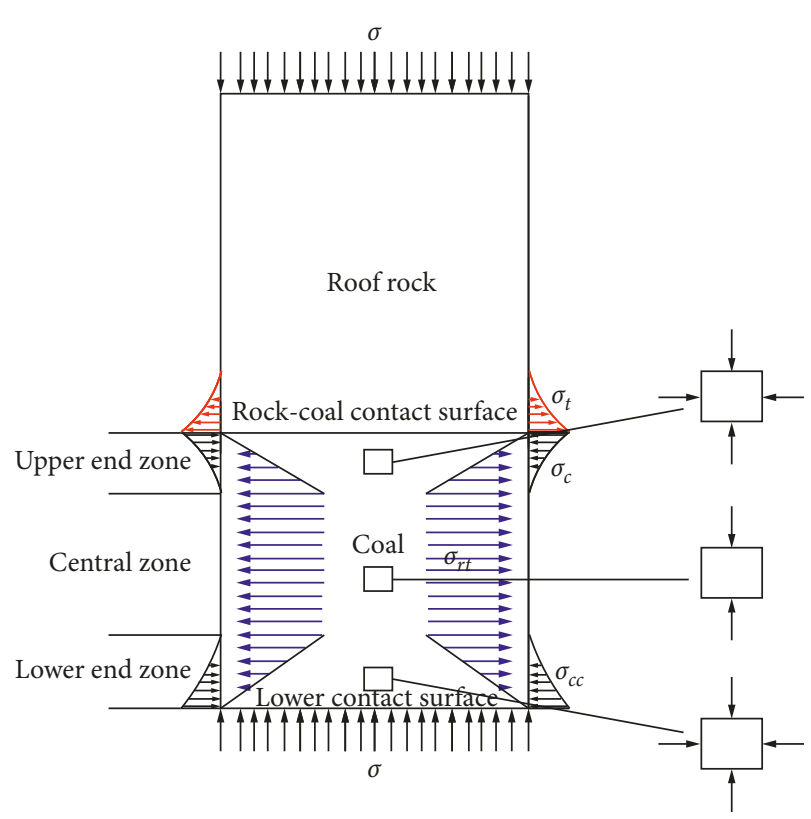

Figure 4: Stress state of the coal in the composite sample.

enhanced to a certain extent by the coal. The tensile stress $\sigma_{t}$ for sandstone and compressive stress $\sigma_{c}$ for coal at the contact surface were derived, which was named as the interface effect $[9,10]$. The value of $\sigma_{t}$ was equal to that of $\sigma_{c}$. The directions of $\sigma_{t}$ and $\sigma_{c}$ were opposing, and they decreased gradually towards the centre of the coal or rock. However, due to the boundary effect of the lower rigid pressure head, a compressive stress $\sigma_{c c}$ for coal was generated on the lower contact surface. In addition, $\sigma_{c c}$ decreased gradually towards the coal. The lower pressure and higher strength head possessed a greater elastic modulus and lower Poisson's ratio; thus, the relative deformation between the coal and lower pressure head was larger than that between the coal and sandstone. Therefore, $\sigma_{t}, \sigma_{c}$, and $\sigma_{c c}$ satisfy the following equation [2]:

$$
\sigma_{c c}>\sigma_{c}=\sigma_{t} .
$$

The coal near the upper and lower contact surface, which resisted destruction, was in triaxial compression. The coal in the central part of the test samples was still subject to uniaxial compression [2]. Radial tensile stress $\sigma_{r t}$ was generated within the coal under $\sigma$, which decreased gradually towards the outer boundary of the coal, and the radial tensile stress was relatively low at both ends of coal but was high in the centre $[2,23]$. Therefore, the tensile fracture occurred easily, which led to an increased likelihood of the formation of X-typed or hourglass cracks in the coal. This could be verified with the mixed failure model of X-typed shear failure and splitting failure of the composite samples.

The horizontal penetrative crack in the coal was predominantly compacted under $\sigma$, and there was little difference in the radial tensile stress near the two crack surfaces. Consequently, the deteriorating influence of the horizontal penetrative cracks on the structural strength was lowest in 
this study. Compared with the A-1 composite sample (the intact composite sample), the UCS of the A-4 composite sample decreased by $4.37 \%$, as shown in Figure 3. For the A-2, A-3, and A-5 composite samples, the surface vertical crack and vertical penetrative crack initiated easily and propagated under the influence of the radial tensile stress, which aggravated the coal failure and reduced the coal's strength. The structural strength of the composite sample decreased. Moreover, the properties of the pre-existing coal cracks, such as crack distribution and crack geometry, determined the deteriorating influence on structural strength. The radial tensile stress reached its relative maximal values near the central area of the coal. Therefore, the vertical penetrative crack through the centre of the coal exerted the largest deteriorating influence on structural strength. Compared with the intact composite sample, the UCS of the A-5 composite sample decreased by $37.72 \%$. The UCS of the A-2 composite sample with surface vertical cracks in the coal decreased by $20.11 \%$ compared with that of the intact composite sample, and the UCS of the A-3 composite sample with vertical penetrative cracks through the coal sides decreased by $12.18 \%$. The degree of reduction in the UCS of the A-2 composite sample was larger than that of the A-3 composite sample. Two main reasons were proposed for this phenomenon.

One was that the region between the two vertical penetrative cracks may be the main load-bearing structure of the coal, and the vertical penetrative cracks thus had little effects on the coal's strength. From the beginning of the loading to the macrofailure initiation (MFI) point, the fluctuation degree of the AE signal (energy index) of the A-2 composite sample was higher than that of the A-3 composite sample, as discussed in Section 3.4, and these illustrate that the initial internal damage in the coal in the A-2 composite sample was higher than that in the A-3 composite sample. The initial internal damage reduced the strength of A-2 composite sample. Therefore, the UCS of the A-2 composite sample might be lower than that of the A-3 composite sample.

\subsection{Macrofailure Initiation (MFI) Characteristics of Com-} posite Samples. The first macrofailure point in the composite sample is considered to be the MFI point, which represents the beginning of the macrofailure in the composite sample. The MFI point is well reflected in the stress-strain curve of the composite sample [5, 11, 22]. When the composite sample undergoes the MFI, a clear turning point is observed in the corresponding stress-time curve, as shown in Figure 5. The corresponding axial stress is defined as the macrofailure initiation stress (MFIS) in this test. As the composite sample undergoes macrofailure, the energy of fracture or damage is rapidly released, which generates the AE. The energy index is chosen as the $\mathrm{AE}$ characteristic parameter which represents the AE signal intensity in this study. The energy index is the waveform envelope area of the AE waveform signal, and thus has no associated unit. The energy index corresponding to the MFI point appears as a peak value (Figure 5). The macrofailure initiation stress (MFISs), energy indexes caused by the MFI, and the macrofailure initiation models
(MFIMs) of the composite samples as observed are presented in Table 3.

In Table 3, the MFI of the composite samples occurred within the coal are shown. Wang et al. proposed that additional tensile stress vertical to the loading direction developed around the original defects in the rock sample under uniaxial loading [22]. When the additional tensile stress exceeded the rock sample tensile strength, crack coalescence and macrocracks occurred in the body and surface boundaries of the sample, indicating an active MFI process. Yin et al. observed that the energy stored in the composite sample could potentially be released rapidly during the MFI process, followed by a rapid surface spalling of the coal [22], similar to the MFI fracturing processes noted in composite samples A-3, A-4, and A-5. In addition, the surface spalling failures were generally located adjacent to the original defects. This process was too rapid to be captured with the digital video camera. The additional tensile stress was [24]

$$
\Delta \sigma=-\frac{1}{6} \frac{l}{\eta T} k \sigma_{0}\left(1-e^{(\eta / l) t}\right),
$$

where, $\Delta \sigma$ is the additional tensile stress; $l$ is scale of the defects, which predominantly refers to the length, width, and depth of the original defects; $T$ is the continuous loading time; $\eta$ is the additional tensile stress relaxation rate; $k$ is the stress concentration coefficient of materials; $\sigma_{0}$ is the axial stress; and $t$ is the time variable. When $\Delta \sigma \geq \sigma_{T}$, the MFI occurred in the coal. $\sigma_{T}$ is the tensile strength of coal.

In equation (2), the additional tensile stress demonstrated a positive relationship with $l$ under the same conditions. Generally, the larger the $l$ was, the greater the value of $\Delta \sigma$. For the intact composite sample (A-1 sample), $l$ was relatively small. A large value of $\sigma_{0}$ was needed to satisfy $\Delta \sigma \geq \sigma_{T}$, and the MFI occurred in the coal. The corresponding MFIS was the largest noted amongst all the samples at $45.21 \mathrm{MPa}$. The macrocracks initiated from the vertical penetrative crack (in A-3 and A-5 composite samples) and from the surface vertical crack (in composite samples A-2 and A-4). $l$ of the vertical penetrative crack was larger than that of the surface vertical crack. A small value of $\sigma_{0}$ could make $\Delta \sigma \geq \sigma_{T}$, and the MFISs of samples A- 3 and A-5 were lower than those of A-2 and A-4 composite samples. Compared with the A-1 composite sample, the MFIS of composite samples A-2, A-3, A-4, and A-5 decreased by $30.52 \%, 35.01 \%, 23.27 \%$, and $54.39 \%$, respectively (Figure 6). The length of the surface vertical crack from which the macrocrack initiated in composite sample A-2 was larger than that of composite sample A-4 (Table 1), and the MFIS of composite sample A-2 was smaller than that of composite sample A-4. The MFIS of composite sample A-3 was larger than that of composite sample A-5.

In addition, the ratio of MFIS to UCS for the intact composite sample was $97.13 \%$, close to $100 \%$. This indicated an instantaneous process from macrofailure to the complete failure of the composite sample. Moreover, the ratios of MFIS to UCS of the composite samples containing preexisting coal cracks were between $50.73 \%$ and $84.46 \%$, indicating a progressive process from the point of macrofailure 


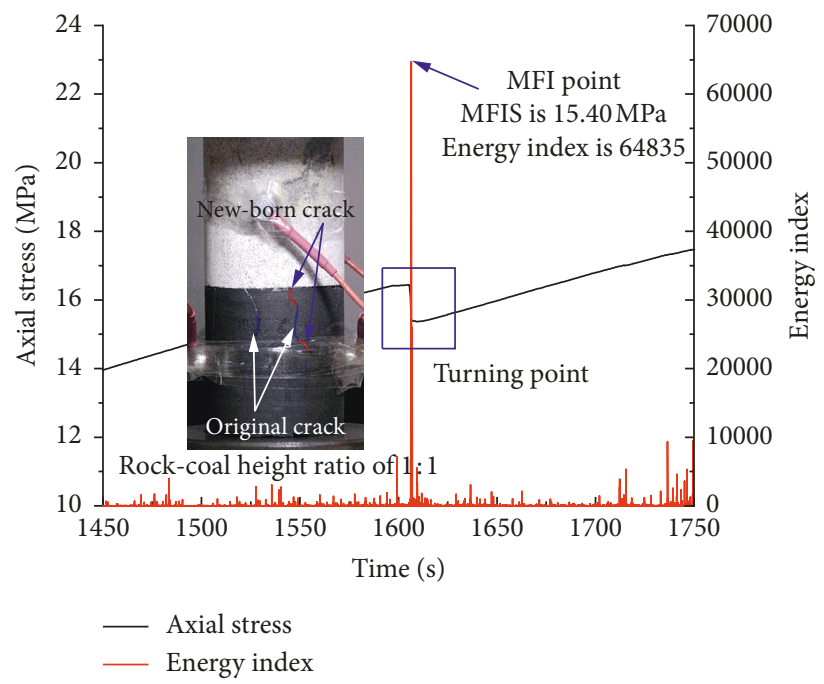

FIGURE 5: Macrofailure initiation of the rock-coal composite sample [5].

TABLE 3: MFIS, energy index peak caused by the MFI, and MFIM.

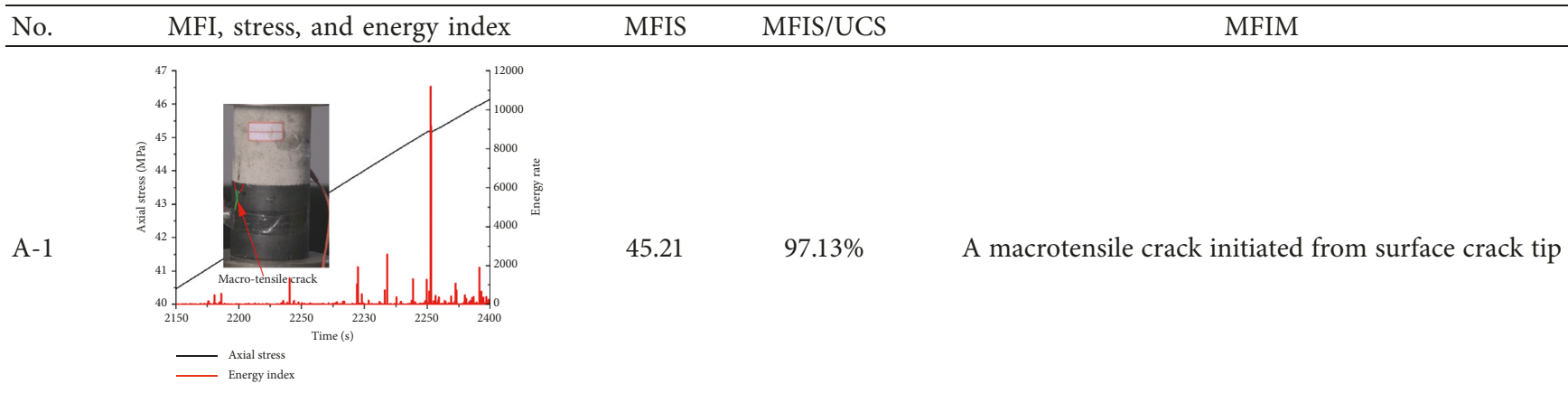

20000
A-2

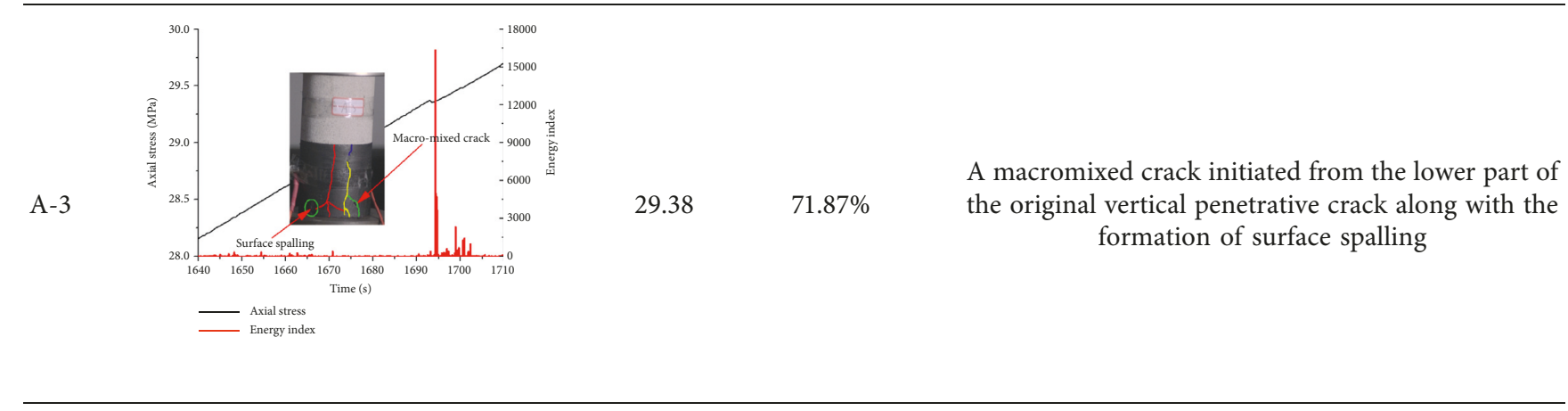


TABLE 3: Continued.

No. MFI, stress, and energy index $\quad$ MFIS

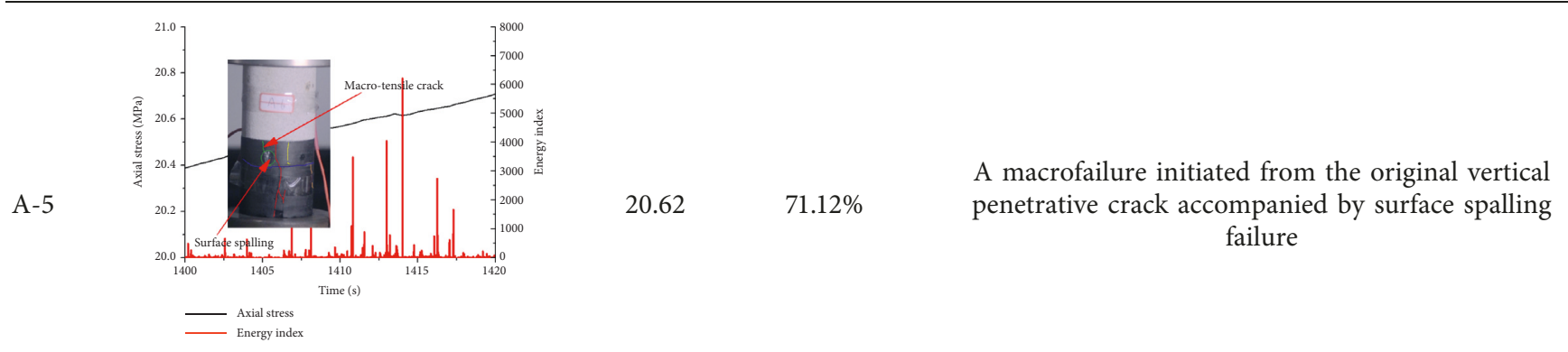

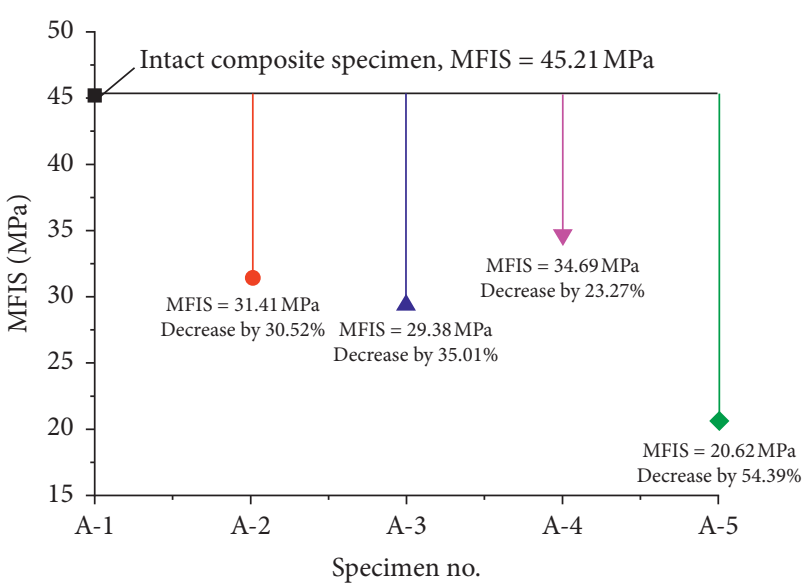

FIGURE 6: MFIS comparison.

to complete failure. The failure characteristics of the composite samples are further analysed and discussed in the following sections.

3.3. Macrofailure Patterns of Composite Samples. The macrofailure pattern photos of the composite samples are shown in Figure 7. The failures of composite samples A-1 to A-4 occurred predominantly within the coal, whereas no apparent failure was observed in the sandstone. The upper or lower parts of the coal were tapered, indicating that the coal was subject to shear stress and was destroyed due to X-typed shear failure. These results were similar to those seen in the failure model of the coal in the rock-coal-rock composite sample offered by Liu et al. [2]. Some vertical tensile cracks were also observed in the coal of composite samples A-1 to A-4, indicating the occurrence of splitting failure, as shown by the red lines in Figure 7. The failure models of A-1 to A-4 composite samples were mixed failure models incorporating both X-typed shear failure and splitting failure. Moreover, both the coal and sandstone in composite sample A-5 were destroyed. The failure of the coal was mainly due to splitting failure accompanied with a small X-typed shear failure, and the sandstone showed a splitting failure induced by crack propagation in the coal. The radial tensile stress reached a maximum near the central area of the coal. The vertical penetrative crack through the centre of the coal in composite sample A-5 facilitated the tensile fracture under the influence of the radial tensile stress. The tensile fracture may have caused the failure of the coal which then induced the structural failure of the composite sample.

3.4. Analysis of the Deformation and Failure Process. In order to further discuss the effects of the pre-existing coal cracks on the failure characteristics of the composite samples, the deformation and failure processes of the composite samples were analysed, as shown in Figure 8. According to the various stages of rock deformation under uniaxial loading and the definition of MFI, the deformation and failure process of the composite sample could be divided into three stages $[9,22]$. These were Stage I: initial compaction stage (segment OA), Stage II: linear elastic stage (segment AB), and Stage III: macrofailure stage (from point $B$ until the end).

The pre-existing coal cracks affected the deformation and failure process of the composite sample. Compared with the composite samples with pre-existing coal cracks, the Stage III process of the intact composite sample (A-1 


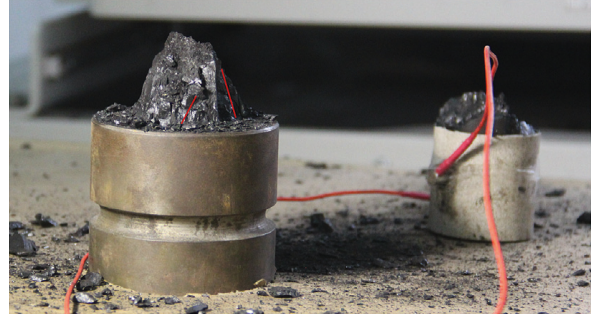

(a)

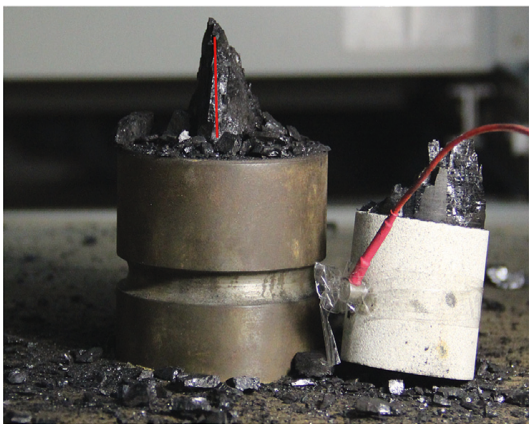

(c)

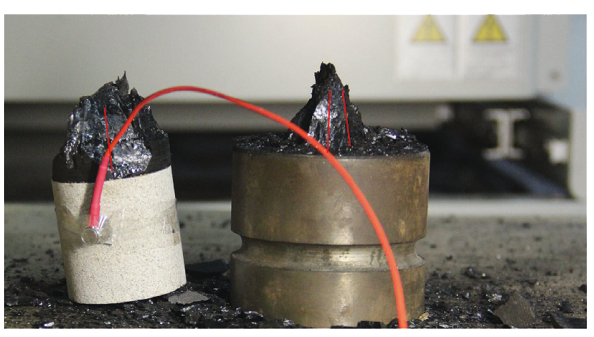

(b)

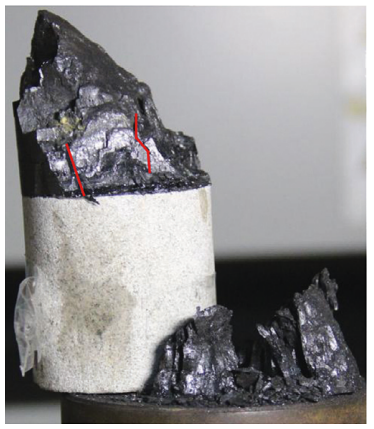

(d)

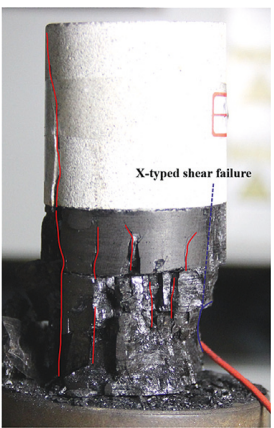

(e)

Figure 7: Typical failure models of composite samples. (a) A-1. (b) A-2. (c) A-3. (d) A-4. (e) A-5.

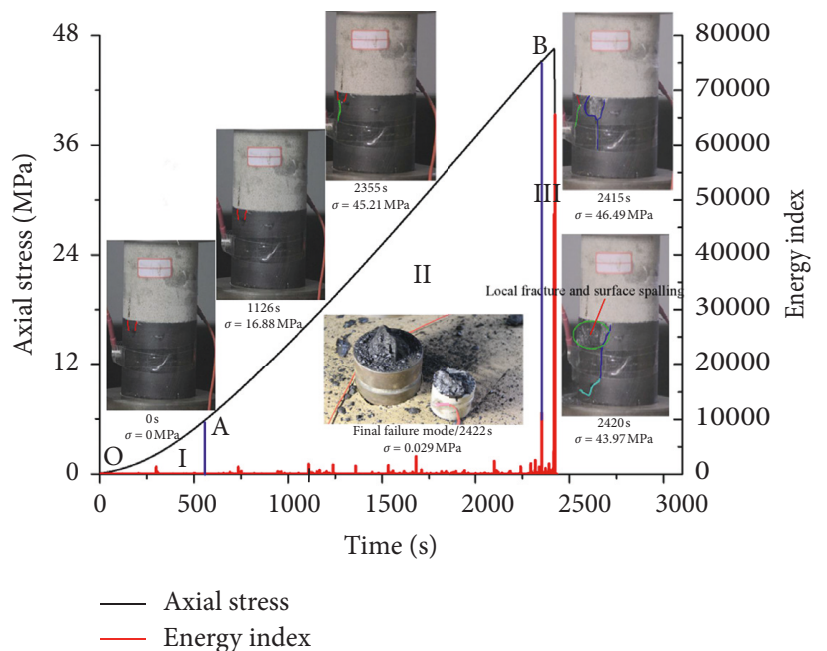

(a)

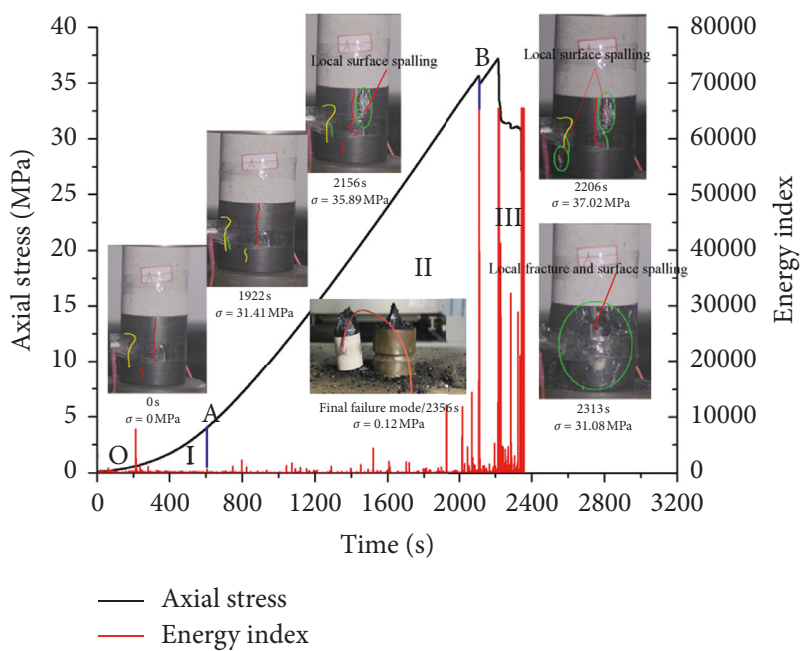

(b)

Figure 8: Continued. 

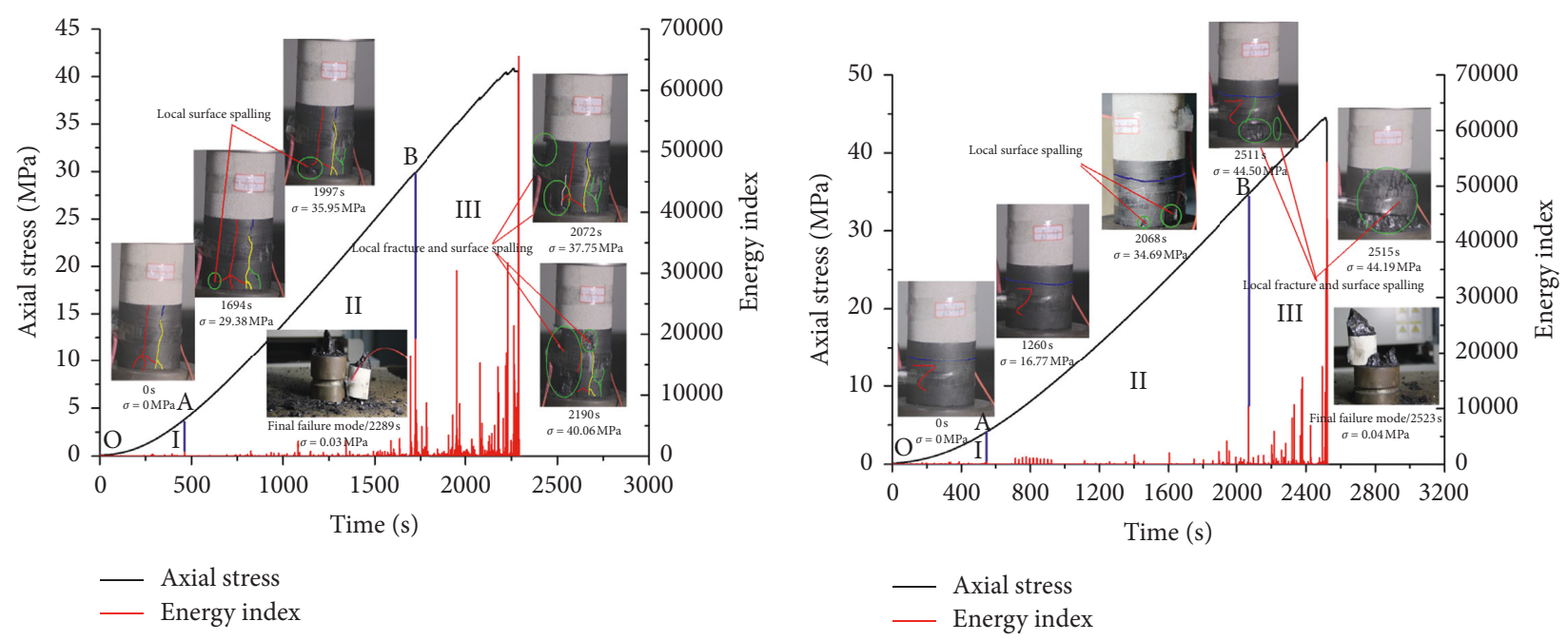

(c)

(d)

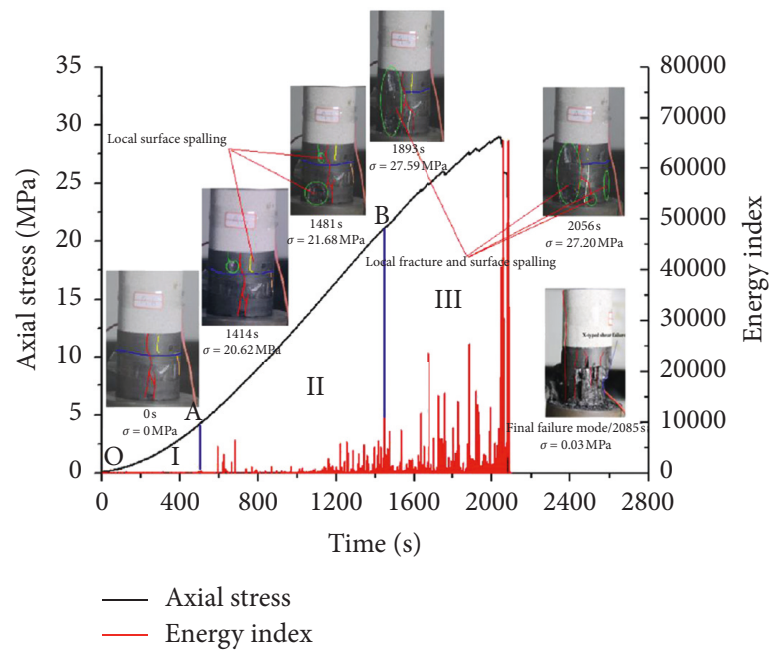

(e)

Figure 8: Deformation and failure processes of composite samples. (a) A-1. (b) A-2. (c) A-3. (d) A-4. (e) A-5.

composite sample) was too short to release the elastic energy predominantly stored in Stage II. The corresponding failure was instantaneous and violent, and thus could cause dynamic hazards. The pre-existing coal cracks promoted the MFI occurrence, shortened the Stage II process, and extended the Stage III process. The composite samples with pre-existing coal cracks exhibited progressive failure. The voids and cracks in the coal and rock and the compaction of the interface between them were further compacted under uniaxial loading in Stage I, and the energy index was stable and remained at a low level. The elastic energy was predominantly stored in the composite sample in Stage II, and slight fluctuations occurred in the energy index without points of abrupt increase due to the initial microcrack initiation and propagation, especially in composite sample A-2. In Stage III, macrocracks predominated, initiating and propagating within the coal. Original and new cracks propagated and coalesced, followed by the localized fractures and spalls. This process consumed a large amount of elastic energy and decreased the structural integrity of the composite sample. Therefore, the tendency for dynamic hazards to be caused under the conditions modelled with the composite samples with the coal's pre-existing cracks was reduced. The corresponding energy index demonstrated significant fluctuations with a greater number of peak values.

During deep coal mining, close attention must be paid to the areas of coal seam with horizontal penetrative cracks. In these areas, some measures should be adopted to decrease the occurrence probability of rockburst disasters caused by the instability and failure of the composite system of coal seam and roof rock. These measures include coal seam infusion, advanced bore decompression in coal seam and cutting pressure-relief slot in coal seam.

\section{Conclusions}

In this study, uniaxial compression tests were conducted on sandstone-coal composite samples with penetrative cracks or surface cracks in the coal. The effects of the coal's preexisting cracks on the strength, macrofailure initiation 
(MFI), and failure characteristics of composite samples, were analysed. The following conclusions were obtained:

(1) The pre-existing coal cracks weakened the strength, promoted the occurrence of macrofailure initiation (MFI), and affected the failure characteristics of the composite samples. The vertical penetration cracks had much larger effects on strength and MFI occurrence, especially vertical penetration cracks that penetrated through the centre of the coal. Horizontal penetration cracks had much smaller effects on the strength and MFI occurrence.

(2) The MFI caused a step shape in the stress-strain curve, and the energy index reached a peak value. The values of macrofailure initiation stress (MFIS) of composite samples with pre-existing cracks were lower than that of the intact composite sample. The MFI of all composite samples originated at the pre-existing cracks, including the crack initiation of the pre-existing cracks, the formation of the newly-formed macroscopic cracks adjacent to the pre-existing cracks, and the surface spalls caused by crack propagation.

(3) The failures of the composite samples occurred predominantly within the coal and displayed an X-typed shear failure accompanied by a small splitting failure. Both the coal and sandstone were destroyed in the composite sample predominantly containing vertical penetration cracks through the centre of the coal. Failure of the coal occurred through a splitting failure accompanied by a small X-typed shear failure, while the sandstone showed a splitting failure induced by crack propagation in the coal.

(4) The intact composite sample failure involved an instantaneous failure with a significant amount of elastic energy that was rapidly released. There was a high tendency for the occurrence of hazards. Conversely, the composite samples with pre-existing coal cracks presented a progressive failure. From the MFI point to the peak stress point, original and new cracks propagated and coalesced, and then localized fractures and spalling occurred. This process consumed a large amount of elastic energy and decreased the supporting capacity of the composite sample. The tendency for the occurrence of hazards was thus reduced.

\section{Data Availability}

The data used to support the findings of this study are included within the article.

\section{Conflicts of Interest}

The authors declare that they have no conflicts of interest.

\section{Acknowledgments}

This study was supported by the National Natural Science Foundation of China (51904167, 51474134, 51774194,
51874189), Taishan Scholars Project, Taishan Scholar Talent Team Support Plan for Advantaged and Unique Discipline Areas, SDUST Research Fund, Shandong Provincial Natural Science Fund for Distinguished Young Scholars (JQ201612), and Shandong Provincial Key Research and Development Plan (2017GSF17112). The authors thank the Project of Open Research Fund for Key Laboratories of Ministry of Education for safe and efficient mining of coal mine (JYBSYS2019201).

\section{References}

[1] B. Huang and J. Liu, "The effect of loading rate on the behavior of samples composed of coal and rock," International Journal of Rock Mechanics and Mining Sciences, vol. 61, pp. 23-30, 2013.

[2] J. Liu, E. Wang, D. Song, S. Wang, and Y. Niu, "Effect of rock strength on failure mode and mechanical behavior of composite samples," Arabian Journal of Geosciences, vol. 8, no. 7, pp. 4527-4539, 2015.

[3] S. Chen, D. Yin, F. Cao, Y. Liu, and K. Ren, "An overview of integrated surface subsidence-reducing technology in mining areas of China," Natural Hazards, vol. 81, no. 2, pp. 11291145, 2016.

[4] C.-P. Lu, G.-J. Liu, Y. Liu, N. Zhang, J.-H. Xue, and L. Zhang, "Microseismic multi-parameter characteristics of rockburst hazards induced by hard roof fall and high stress concentration," International Journal of Rock Mechanics and Mining Sciences, vol. 76, pp. 18-32, 2015.

[5] S. Chen, D. Yin, N. Jiang, F. Wang, and Z. Zhao, "Mechanical properties of oil shale-coal composite samples," International Journal of Rock Mechanics and Mining Sciences, vol. 123, p. 104120, 2019.

[6] S. J. Chen, D. W. Yin, H. M. Liu, B. Chen, and N. Jiang, "Effects of coal's initial macrocracks on rockburst tendency of rock-coal composite samples," Royal Society Open Science, vol. 6, no. 11, Article ID 181795, 2019.

[7] R.-H. Cao, P. Cao, H. Lin, C. Z. Pu, and K. Ou, "Mechanical behavior of brittle rock-like specimens with pre-existing fissures under uniaxial loading, experimental studies and particle mechanics approach," Rock Mechanics and Rock Engineering, vol. 49, no. 3, pp. 763-783, 2016.

[8] X. L. Li, L. J. Kang, H. Y. Li, and Z. H. Ouyang, "Three-dimensional numerical simulation of bust-prone experiments about coal-rock combination," Journal of China Coal Society, vol. 36, no. 12, pp. 2064-2067, 2011.

[9] D. W. Yin, S. J. Chen, X. Q. Liu, and H. F. Ma, "Effect of joint angle in coal on failure mechanical behavior of roof rock-coal combined body," Quarterly Journal of Engineering Geology and Hydrogeology, vol. 51, no. 2, pp. 202-209, 2018.

[10] D. W. Yin, S. J. Chen, B. Chen, X. Q. Liu, and H. F. Ma, "Strength and failure characteristics of the rock-coal combined body with single joint in coal," Geomechanics and Engineering, vol. 15, no. 5, pp. 1113-1124, 2018.

[11] S. J. Chen, D. W. Yin, B. L. Zhang, H. F. Ma, and X. Q. Liu, "Study on mechanical characteristics and progressive failure mechanism of roof-coal pillar structure body," Chinese Journal of Rock Mechanics and Engineering, vol. 37, no. 7, pp. 1588-1598, 2017.

[12] Z.-H. Zhao, W.-M. Wang, C.-Q. Dai, and J.-X. Yan, "Failure characteristics of three-body model composed of rock and coal with different strength and stiffness," Transactions of 
Nonferrous Metals Society of China, vol. 24, no. 5, pp. 15381546, 2014.

[13] S. J. Chen, D. W. Yin, N. Jiang, F. Wang, and W. J. Guo, "Simulation study on effects of loading rate on uniaxial compression failure of composite rock-coal layer," Geomechanics and Engineering, vol. 17, no. 4, pp. 333-342, 2019.

[14] Z. T. Zhang, J. F. Liu, L. Wang, H. T. Yang, and J. P. Zuo, "Effects of combination mode on mechanical properties and failure characteristics of the coal-rock combinations," Journal of China Coal Society, vol. 37, no. 10, pp. 1677-1681, 2012.

[15] Z. H. Zhao, W. M. Wang, L. H. Wang, and C. Q. Dai, "Compression-shear strength criterion of coal-rock combination model considering interface effect," Tunnelling and Underground Space Technology, vol. 47, pp. 193-199, 2015.

[16] T. B. Zhao, W. Y. Guo, C. P. Lu, and G. M. Zhao, "Failure characteristics of combined coal-rock with different interfacial angles," Geomechanics and Engineering, vol. 11, no. 3, pp. 345-359, 2016.

[17] Y. L. Tan, X. S. Liu, J. G. Ning, and Y. W. Lu, "In situ investigations on failure evolution of overlying strata induced by mining multiple coal seams," Geotechnical Testing Journal, vol. 40, no. 2, pp. 244-257, 2017.

[18] Y. L. Tan, X. S. Liu, B. Shen, J. G. Ning, and Q. H. Gu, "New approaches to testing and evaluating the impact capability of coal seam with hard roof and/or floor in coal mines," Geomechanics and Engineering, vol. 14, no. 4, pp. 367-376, 2018.

[19] B. A. Poulsen, B. Shen, D. J. Williams, C. HuddlestoneHolmes, N. Erarslan, and J. Qin, "Strength reduction on saturation of coal and coal measures rocks with implications for coal pillar strength," International Journal of Rock Mechanics and Mining Sciences, vol. 71, pp. 41-52, 2014.

[20] T. Wang, Y. D. Jiang, S. J. Zhan, and C. Wang, "Frictional sliding tests on combined coal-rock samples," Journal of Rock Mechanics and Geotechnical Engineering, vol. 6, no. 3, pp. 280-286, 2014.

[21] X. Qu, "Experimental study on influence of mechanical properties of roof and floor on stability of strip coal pillar," Master's thesis, Shandong University of Science and Technology, Qingdao, China, 2018.

[22] D. W. Yin, S. J. Chen, W. B. Xing, D. M. Huang, and X. Q. Liu, "Experimental study on mechanical behavior of roof-coal pillar structure body under different loading rates," Journal of China Coal Society, vol. 43, no. 5, pp. 1249-1257, 2018.

[23] M. Serati, H. Alehossein, and D. J. Williams, "Estimating the tensile strength of super hard brittle materials using truncated spheroidal specimens," Journal of the Mechanics and Physics of Solids, vol. 78, pp. 123-140, 2015.

[24] M. Y. Wang, P. X. Fan, and W. P. Li, "The mechanism of splitting and unloading failure of rock," Chinese Journal of Rock Mechanics and Engineering, vol. 29, no. 2, pp. 234-241, 2010. 


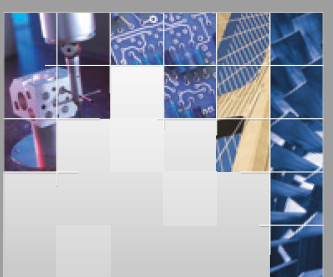

\section{Enfincering}
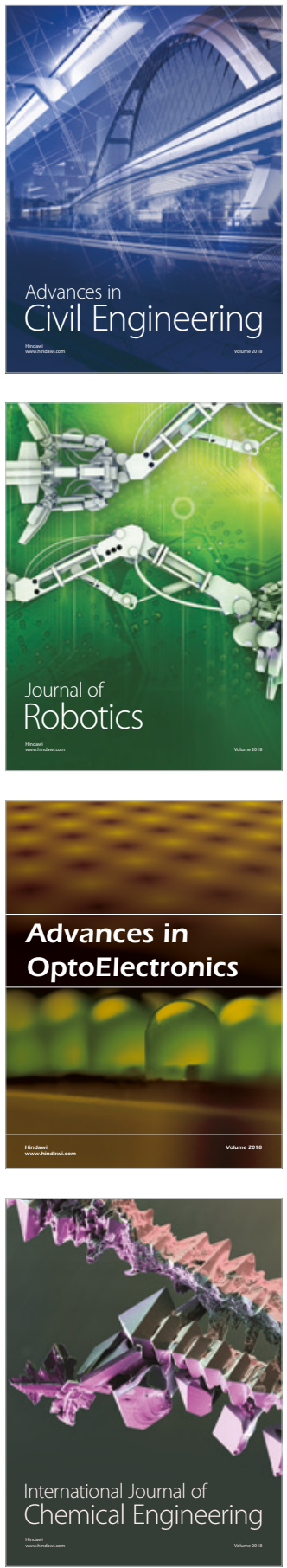

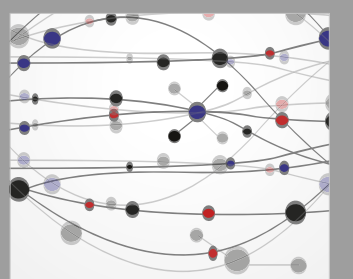

\section{Rotating \\ Machinery}

The Scientific World Journal

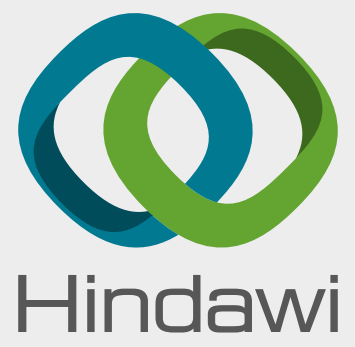

Submit your manuscripts at

www.hindawi.com
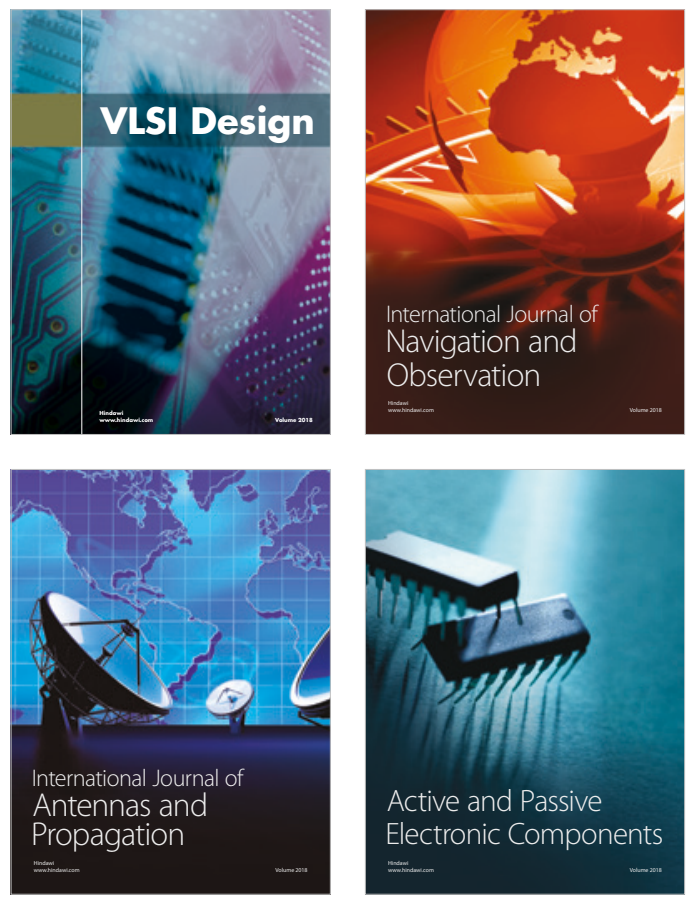
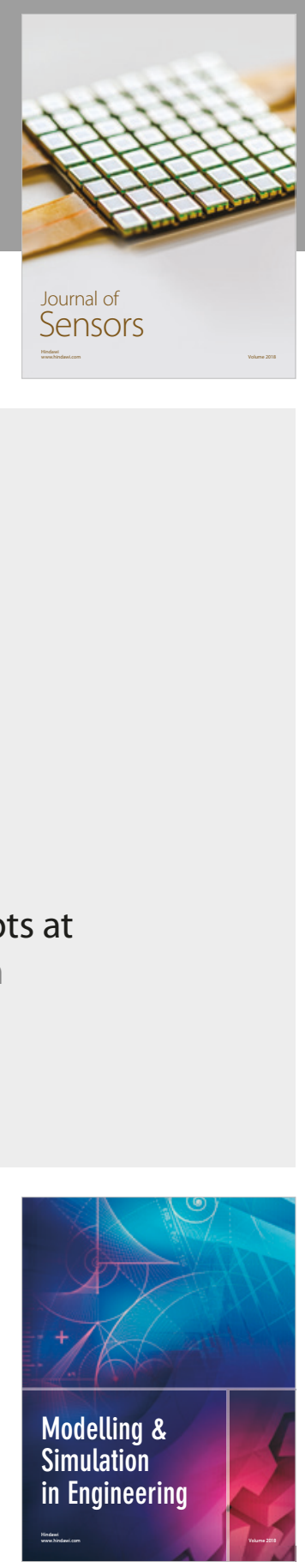

\section{Advances \\ Multimedia}
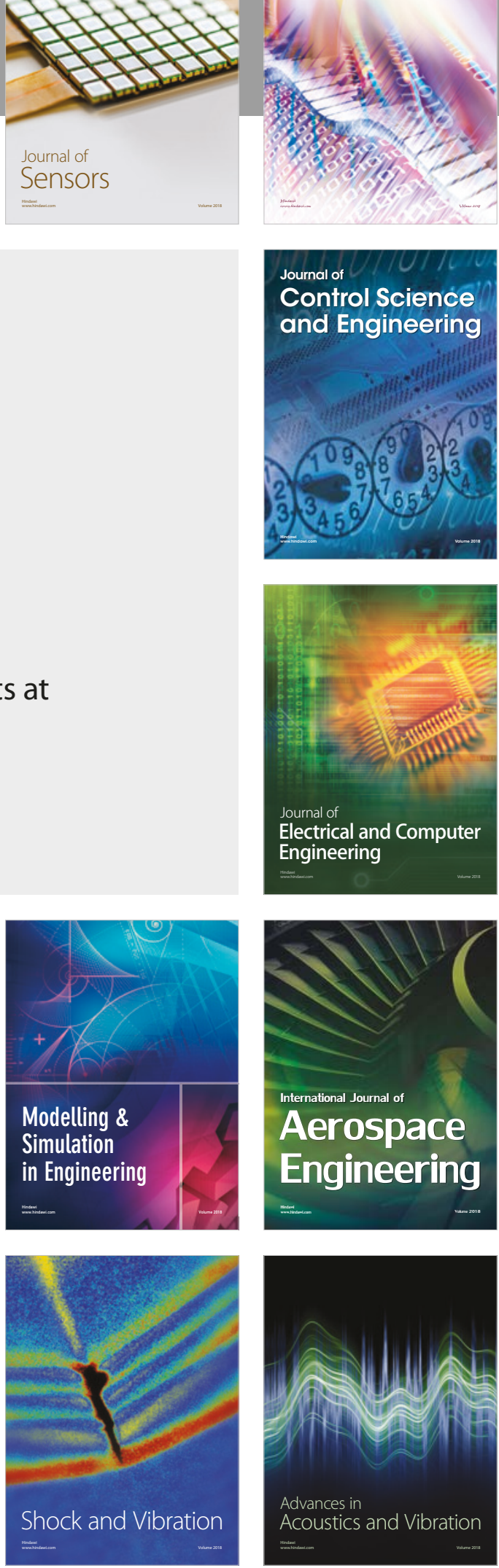